http://jmscr.igmpublication.org/home/ ISSN (e)-2347-176x ISSN (p) 2455-0450

crossref DOI: https://dx.doi.org/10.18535/jmscr/v8i2.133

\author{
Journal Of Medical Science And Clinical Research \\ IGM Publication \\ An Official Publication of IGM Publication
}

\title{
Study of Effect of L-Arginine in IUGR Cases with Its Fetal Outcome
}

\author{
Authors \\ Dr Ritu Kumari ${ }^{1}$, Dr Anjana Sinha ${ }^{2}$ \\ ${ }^{1}$ Senior Resident, Patna Medical College \& Hospital, Patna \\ ${ }^{2}$ Associate Professor, Patna Medical College \& Hospital, Patna
}

\begin{abstract}
IUGR is a major cause of infant mortality \& morbidity worldwide. The current management of IUGR being empirical \& aimed of selecting a safe time for delivery. Acknowledging, the beneficial effect of L-arginine on endothelial vasculature by producing NO through L-Arginine/No Pathway by sterocospeicific enzyme NO SYNTHETASE, \& arginine deficiency may play an important role in causation of IUGR. Starting from $3^{\text {rd }} w k$ of therapy, the umbilical artery pulsatility index were significantly lower in l-arginine then in placebo group. Treatment with L-arginine caused significant increase of middle cerebral artery pulsatility indices \& cerebro placental ratio values. The present study showed that neonates delivered in L-arginine group had higher Apgar score. Supplementary $t / t$ with oral L-arginine seems to be promising in improving fetal well bring \& neonatal outcome as well as in prolonging pregnancy complicated with preeclampsia.
\end{abstract}

\section{Introduction}

Fetal development is dependent on maternal provision of substrate, placental transfer of these substrate. Intrauterine fetal development is a complex multifactorial process.

Foetal growth restriction is a pathological condition in which a fetus has not observed its genetic growth potential regardless of fetal size as a result of suboptimal intrauterine growth condition. IUGR is defined as fetus of birth of $<10^{\text {th }}$ percentile of those born at same gestational age or two standard deviation below the population means. IUGR complicates $3-10 \%$ of pregnancies \& $20 \%$ of stillbirth are IUGR. The incidence of low birth wt. babies in India varies from 15 to $25 \%$, of these nearly $50 \%$ are due to IUGR.
Pathophysiology of normal fetal growth fetal growth divided into 3 phases. First phase - phase of hyperplasia (first $16 \mathrm{wk}$ ).

$2^{\text {nd }}$ Phase - Includes both hyperplasia \& hypertrophy (up to $32 \mathrm{wk}$ ).

$3^{\text {rd }}$ phase - growth occurs via hypertrophy (after 32 wk) \& during.

This phase most fetal fat $\&$ glycogen deposition occur.

Growth rate during these 3 cells growth phases are from $5 \mathrm{gm} /$ day at $15 \mathrm{wks} 15$ to $20 \mathrm{gm} / \mathrm{dl}$ at $24 \mathrm{wk}$ \& 30-35 gm/dl at 34 wks.

Etiology - major risk factor for IUGR include chromosomal abnormality, congenital infection, poor maternal health (DM, HT, anemia, cardiac, renal \& hepatic ds) Pre-eclampsia, smoking environment pollutants, drug \& alcohol abuse, maternal age $>35 y r \&$ placental pathology, other 
risk factor are multiple pregnancy primiparity, maternal malnutrition, low socio economic status.

\section{Complication of IUGR Antepartum}

- Fetal hypoxia \& acidosis.

- Stillbirth.

- Oligohydramnios

Intrapartum $\rightarrow$ There is high incidence of intrapartum hypoxia leading to meconium stained liquor.

Neonatal - Respiratory distress syndrome

Meconium aspiration syndrome

Pulmonary hypertension due to vasoconstriction of vasculature of lungs.

Encephalopathy due to hypoxic ischemic brain injury.

- Hypoglycemia

- Intraventricular hemorrhage \& periventicular leuconalacia.

- Hypocalcemia.

- Hypersiscosity syndrome- chronic intrauterine hypoxia leads to stimulation of fetal bone marrow \& high hematocrit.

\section{Long term sequele}

- Increased incidence of coronary ds, arterial hypertension \& DM in adult life.

- Lower, neuro developmental score

Effect of Maternal Nutrition on Gestational Wt

\section{Gain}

The basis study by the supplementation with multiple micronutrients intervention Trial (SUMMIT) study group [(2008)30] almost 32,000 Indonesian women were randomized to receive micronutrients supplementation or only iron \& folate tablets. Infants of those receiving the supplement had lower risks of early infant mortality \& low birth wt and had improved childhood motor \& cognitive abilities (Prado, 2012) ${ }^{[3]}$.

\section{Investigation}

Routine $\rightarrow$ CBC, Blood Sugar (fasting \& Post prandial).

Serology : HIV, HbsAg, Anti HCV, VDRL

- $\quad \mathrm{R} / \mathrm{E}$ of urine

- Thyroid profile
USG of gravid uterus for fetal well being placental localization, colour Doppler (HC, AC, AFI) 20-wks absence of uterine artery notching.

Special investigations when Reqired- Dopplar

Velocimetry of

Umbilical artery

Middle cerebral artery

Ductus Venosus

Role of L-arginine in pregnancy \& fetal growth.

L-arginine is a semi essential amino acid acting as a substrate for synthesis of No. No has a diverse role in obstetrics as it plays a vital role in labour cervical ripening, preeclampsia \& IUGR, Larginine is also reported to improve growth hormone releasing hormone secretion and as a consequence increased in plasmatic growth hormone influencing somatic growth. It is also suggested that it may play significant role in fetal growth by stimulating insulin secretion \& as a precursor of both polyamine synthesis \& No production. Thus decreased in nitric acid dependant vasodilatation \& excess formation of reactive $\mathrm{O} 2$ species could explain poor placental perfusion.

\section{Maternal \& Methods}

Study design - Prospective clinical study.

Selection of cases - cases will be selected from patient admitted in the Department of obs \& gynae of PMCH (Duration April 18 to March 19) Inclusion criteria - The pt b/w 24-36 wk of gestational age in singleton pregnancy complicated by asymmetric IUGR.

Exclusion criteria - Pt asso with symmetric IUGR, HTN, DM, smoking Renal disease, fetal malformation.

Method- All selected pt b/w 24-36 wk in singleton pregnancy complicated by IUGR will be administered $3 \mathrm{~g}$ of L-Arginine \& its beneficial effect on fetal outcome will be studied. The monitoring of fetal well being will be done by fetal heart sound \& fetal movement count as daily basis \& USG \& colour Doppler on weekly basis. 
Result $\&$ analysis - The student ' $t$ ' test was used to determine whether there was a statistical difference between two group in parameters measure.

A total number of 100 cases of pregnancies with fetal growth restriction were supplemented with
L-Arginine and its effect on neonatal outcome was studied \& analysed as follows.

100 cases of IUGR pt. was studied \& they all met criteria of IUGR mentioned above.

\section{Distribution a/c to gravida of $\mathrm{pt}$.}

\begin{tabular}{|l|c|c|c|}
\hline Gravida & No. of pt. & Valid \% & Commutative \\
\hline $1^{\text {st }}$ Preg. & 44 & $44 \%$ & $44 \%$ \\
\hline $2^{\text {nd }}$ Preg. & 35 & $35 \%$ & $35 \%$ \\
\hline $3^{\text {rd }}$ Preg. & 14 & $14 \%$ & $14 \%$ \\
\hline $4^{\text {th }}$ Preg. & 7 & $7 \%$ & $7 \%$ \\
\hline
\end{tabular}

Table revealed that the maximum no of cases minimum no. of cases i.e. $7 \%$ in the $4^{\text {th }}$ were observed in primigravida i.e. $44 \%$ \&

pregnancy.

Distribution of cases on the basis of gestational age when they were identified for treatment.

\begin{tabular}{|l|c|c|}
\hline Gestational age in wks & No. of cases & $\%$ \\
\hline$<26 \mathrm{wk}$ & 3 & $3 \%$ \\
\hline $26-29 \mathrm{wk}$ & 12 & $12 \%$ \\
\hline $30-33 \mathrm{wk}$ & 37 & $37 \%$ \\
\hline $34-36 \mathrm{wk}$ & 48 & $48 \%$ \\
\hline
\end{tabular}

Measurement of the height of the fundus of the uterus of the time of diagnosis in different periods of gestations

\begin{tabular}{|l|c|c|c|}
\hline Gestational wk & $\begin{array}{c}\text { No. of cases observed } \\
\text { with percentage n=100 }\end{array}$ & $\begin{array}{c}\text { Mean height of } \\
\text { fundus (cm) }\end{array}$ & $\begin{array}{c}\text { Mean height of } \\
\text { fundus in wks. }\end{array}$ \\
\hline $26 \mathrm{wks}$ & $5(5 \%)$ & 20.8 & 22 \\
\hline 28 & $10(10 \%)$ & 21.9 & 24 \\
\hline 30 & $3(3 \%)$ & 24.5 & 26 \\
\hline 32 & $28(28 \%)$ & 25.8 & 28 \\
\hline 34 & $38(38 \%)$ & 28 & 30 \\
\hline 36 & $16(16 \%)$ & 28.7 & 32 \\
\hline
\end{tabular}

Table showed that maximum no. of cases i.e. $38 \%$ were diagnosed at 34 wks of gestation with a 28 wks mean height of fundus which was 30 wks clinically.

Observation of the increase in mean height of the fundus in different gestational periods after L-arginine therapy.

\begin{tabular}{|l|c|c|c|c|c|}
\hline & Mean & SD & SE mean & 't' value & 'P' value \\
\hline Fundal height 28 wk & 25.7 & 1.12 & 0.14 & 20.09 & 0.000 \\
\hline Fundal height 30 wk & 27.7 & 1.08 & 0.14 & 26.99 & 0.000 \\
\hline Fundal height 32 wk & 29.5 & 1.06 & 0.13 & 42.43 & 0.000 \\
\hline Fundal height 34 wk & 31.72 & 1.01 & 0.15 & 54.57 & 0.007 \\
\hline Fundal height 36 wk & 33.42 & 1.10 & 0.46 & 57.69 & 0.005 \\
\hline Absolute increase (mean) 28-36 wk & 8.42 & 86 & 0.13 & 5.194 .57 & 0.000 \\
\hline
\end{tabular}

Table showed that the mean increase of the height of the fundus from $28 \mathrm{wk}$ of gestation to $36 \mathrm{wk}$ in study cases was $8.42 \mathrm{~cm}$ which was statistically significant. 
Observation of the birth of the abdomen at the level of the umbilicus in different gestational periods.

\begin{tabular}{|l|c|c|c|c|c|}
\hline & Mean & SD & SE mean & 't' value & 'P' value \\
\hline Abdominal birth 30 wks & 75.55 & 1.71 & 0.22 & 1.87 & 0.064 \\
\hline Abdominal birth 32 wks & 78.39 & 1.59 & 0.20 & 6.58 & 0.000 \\
\hline Abdominal birth 34 wks & 81.49 & 1.30 & 0.17 & 16.81 & 0.000 \\
\hline Abdominal birth 36 wks & 84.82 & 1.08 & 0.14 & 32.27 & 0.000 \\
\hline Absolute increase 30-46 wks & 11.27 & 1.44 & 0.18 & 23.50 & 0.000 \\
\hline
\end{tabular}

Table showed that the mean increase of the girth of the abdomen in the study group was $11.27 \mathrm{~cm}$ which was found to be statistically significant.

The mean AFI pre treatment was 8.26 and post treatment AFI was 12.8. The improvement in mean AFI an administration of L-Arginine was 4.54 which an analysis was found to be statically significant $(\mathrm{P}$ value $<0.05)$.

\section{Discussion}

This study was conducted in Patna Medical College \& hospital in the department of the obs \& gynaecology. A total of 100 pregnancies with fetal growth instruction were selected for the present study \& were administered L-Arginine orally. The study was conducted during the time period of April 2018 to March 2019.

In the present study Maximum (44\%) were primigravidae. As for as parity is concerned it had been observed by different observer like camillieri (1970) Selivn (1972) Shoham Vardi (1994) that fetal growth restriction were common in primigravida.

In this study it was found that in $65 \%$ of cases hemoglobin was between 8.1-10gm. The studies of Sharma (1989) \& Chhabra (1996) who showed that mothers with anemia have greater chances of having growth restricted baby.

It was also observed that the maximum no of fetal growth restricted cases were diagnosed b/w 34$36 \mathrm{wk}$ of gestation. This showed that there was delay in diagnosis of IUGR cases due to majority of patients not having adequate antenatal checkup.

It was found that maximum no. of case i.e. $38 \%$ were diagnosed at 34 wks of gestation when mean fundal height was $28 \mathrm{~cm}$ corresponding to $30 \mathrm{wks}$ of gestation clinically.
Similar observation by Beazley

Cnatlingius (1985) \& Crorg (1993) corroborated with this study.

Also the mean increase in fundal height in study cases on administration of L-Arginine were $8.42 \mathrm{~cm}$ and this was statistically significant.

As far as girth of the abdomen is concerned, in the present study the total increase in mean girth of the abdomen in study cases on administration of L-Arginine orally were $11.27 \mathrm{~cm}$. McCarry stated that abdominal girth measurement have got no value in assessing fetal growth. Mathai (1987) found that fundal height have got higher sensitivity, satisfactory specificity \& significant inter and intra observer variation as compared to abdominal girth.

The improvement in mean AFI of 4.54 was found to be statically significant \& was supported by studies conducted by Dois (1998) Magnan (2003) \& Malhotra (2004).

However these observation require further studies in larger population.

\section{Summary}

- IUGR is a major cause of infant mortality \& morbidity worldwide \& may be associated with an increased risk of metabolic \& physiological disorders later in life.

- In the present study 100 cases of pt in 24-36 wk of gestation with asymmetric IUGR were administered L-Arginine orally \& its effect on fetal outcome was observed.

- Maximum no. of fetal growth restricted cases in the study were observed in primigravida $44 \%$ \& Minimum no. of cases i.e. $7 \%$ were fourth pregnancy $\&$ above.

- Maximum number of cases belonged to the lower \& lower middle class group. 
- Maximum number of cases i.e. $65 \%$ have hemoglobin in range of 8.1-10gm.

- Mean increase in height of fundus from 28 weeks onward till term was $8.42 \mathrm{~cm}$ in study cases after administration of L-Arginine orally which was found to be statistically significant.

- Mean increase of the girth of the abdomen from 30 weeks onwards till term was $11.27 \mathrm{~cm}$ in study cases after administration of -Arginine was found to be statically significant. This is showed that L-Anginine has a role in improving fetal growth as evidenced by increase in fundal height \& abdominal girth from the time of admission to time of delivery.

- Ultrasonography is the most important tool presently at hand to diagnose fetal growth restriction.

- L-arginine $\mathrm{t} / \mathrm{t}$ improves pregnancy outcome \& enhance birth wt.

\section{Conclusion}

One of the primary aims of antenatal care is to identify foetus with a significant growth lag \& ensure prompt treatment.

The prenatal diagnosis of fetal growth restriction presents a formidable obstetric challenge due to limitation in accurate measurement of fetal wt since gestational age is often not precisely known. The current management of intrauterine growth restriction is empirical.

Acknowledging the beneficial effect of LArginine holds promise in halting the course of fetal growth restriction.

L-Arginine, a nutritionally essential amino acid for the fetus plays important role in uteroplacental circulation by being a source of nitric oxide. Thus it is useful in asymmetric fetal growth restricted cases where uteroplacental insufficiency is the main pathological mechanism.

This study concluded that L-Arginine improves fetal outcome. Administration of L-Arginine increases liquor volume \& birth weight. There was redued rate of neonatal complication. No adverse reaction were seen on administration of drug.

Further larger studies are required on L-Arginine as a primary treatment of pt. with asymmetric fetal growth restriction.

\section{References}

1. Divon MY, Hsu HW. Maternal and fetal blood flow velocity waveforms in intrauterine growth retardation. Clin Obstet Gynecol. 1992;35:156-171.

2. Biswas R, Dasgupta A, Sinha RN, Chaudhri RN. An epidemiological study of low birth weight newborns in the district of puruliya, West Bengal, India 2008;52(2)65-71.

3. Gluckman PD, Hanson MA. The consequences of being born small: an adaptive perspective. Horns Res. 2006;65:5-14.

4. Mari G, Hanif F. Intrauterine growth restriction: how to manage and when to deliver. Clin Obstet Gynecol. 2007; 50:497-509.

5. Sankaran S, Kyle PM. Aetiology and pathogenesis of IUGR. Best Pract Res Clin Obstet Gynaecol. 2009;23(6)765-777. 